In the cases under discussion there was no doubt, at any time, so far as could be judged by ophthalmoscopic examination, that the retinal tears were occluded by exudate. At first this occlusion would be of a cellular and fluid character and so would permit fluid to pass through it. Later, with the formation of fibrous tissue, such fluid filtration would be less free and eventually be cut off by the formation of firm adhesions between the retina and the choroid adjacent to the edges of the retinal tear.

It is probable that something of this nature occurred in these cases, the retinal tear becoming firmly sealed and the inter-retinal fluid gradually undergoing absorption as the hydrostatic equilibrium of the vitreous and the intra-ocular pressure became adjusted or re-established.

\title{
THE RESULT OF ORTHOPTIC TREATMENT IN DIVERGENT STRABISMUS
}

\section{BY}

\author{
Sheila Mayou
}

LON DON

THE purpose of this article is to consider the effects of orthoptic treatment on a series of cases of divergent strabismus of various types. As will be shown, orthoptic treatment plays an important part in every case, only a small number finally coming to operation. Of those operated on, all with the exception of one, had had previous training, which had developed fusion and some power of adduction before the operation, so that afterwards the desire for binocular vision enhanced and consolidated the success.

Out of 800 consecutive cases I find that 93 are cases of divergent strabismus. ${ }^{*}$ Of these 93 cases, 48 were emmetropic, 26 were hypermetropic, and 17 were myopic. The high percentage of these emmetropic cases occurring in this series is noteworthy, and I hope to show that these patients are the most favourable to treat.

It is well-known that the majority of convergent squints are hypermetropic and are often spontaneously cured by correcting the error of refraction. In my cases of divergent strabismus there is no error to correct, so that the improvement shown must be due to the exercises only, there being no other treatment which maly have been responsible for the cure.

\footnotetext{
* Constant concomitant (monocular or alternating) and occasional or periodic divergences are all included. Simple exophorias without demonstrable divergence are not included.
} 
A further point of interest which is noteworthy, is the very small percentage of cases that are associated with amblyopia, even in the unilateral divergent cases it does not occur frequently.

Age of onset.-Of these 93 cases I have an accurate history as to the age of onset in 58 per cent., and it is interesting to note that of 36 emmetropic cases 17 are supposed to have squinted since birth and a further nine cases within the first year. A high percentage of these cases come under the heading of periodic or ocćasional squint which I will discuss later. These cases are not considered to be the same as excessive exophorias, though it is possible that the cases beginning in adult life are due to "breakdown exophorias." Of the 12 hypermetropic cases four were noticed from birth and the ages of the three that developed after 10 years of age were 14, 21 and 29 years respectively. Of the 10 myopic $\overrightarrow{\dot{\omega}}$ cases only two were noticed from birth and four developed after the age of 10 years. The respective ages of these four were three $\frac{}{3}$ of 16 years and one of 35 years.

The following is a table of these 58 cases showing the age of onset :-

$\begin{array}{llccc}\text { AGE } & & \text { EMMETROPIC } & \begin{array}{c}\text { HYPER- } \\ \text { METROPIC }\end{array} & \text { MYOPIC } \\ \text { To 1 year... } & \ldots & 26 & 4 & 3 \\ 2-4 \text { years ... } & \ldots & 5 & 4 & 1 \\ 5-10 \text { years } & \ldots & 5 & 1 & 2 \\ \text { Over 10 years } & \ldots & 0 & \frac{3}{12} & - \\ & & \frac{1}{36} & 10\end{array}$

Attendances.-The number of visits necessary to effect a cure varies in every case. In some cases seven lessons have proved sufficient with home exercises, but in others it has taken 50 lessons and homework to obtain a satisfactory result. Where there is no binocular vision present and a patient lives in or near London he generally attends the clinic three times a week until he can manage home exercises, and then twice a week. When he has made good progress and it is seen that the homework is proving beneficial he is then allowed to work at home only and attend the clinic for supervision. This, of course, is only possible when the parent of the child or nurse will take sufficient interest to see that the exercises are carried out every day. Intensive fortnightly or threeweekly courses are arranged in the holidays for children who live in the provinces and home exercises are carried out in the interim.

Methods and instruments.-As far as possible I will endeavour to outline the stages of treatment in connection with the home $\mathrm{\omega}$ exercises. All cases as soon as it is possible are given home exercises to practise between their lessons, and the instruments they use are hired from their opticians at a very low rate. 
Where the patient has little or no binocular vision it is not possible to have any homework and all exercises are given on the synoptophore or the synoptiscope, as it is possible with these two machines to watch the corneal reflexes. When simultaneous macular perception has been obtained the case is then given a cheiroscope or a strabismuscope to decrease the area of suppression and develop simple fusion by the use of simple toys.

Tracings are given and a more advanced set of toys used to strengthen the fusion. At the clinic the child is taught to fuse on the synoptophore by superimposing two similar objects on top of each other, and fusion exercises are given on the myoscope or myoculator. Having developed the fusion sense it is necessary to increase the power of adduction, if this is very weak a Cruise stereoscope with either plain fusion pictures or stereoscopic pictures is given for homework. When the adduction is $15^{\circ}$ or over I have found that a Worth's amblyoscope has proved to be very valuable and has increased the adduction to about $40^{\circ}$. Another small instrument that has proved useful is a small diploscope and the patient is taught to control his eyes by going through the four exercises.

At the clinic the power of adduction is increased by working on convergence exercises on the synoptophore, the variable prism stereoscope and on the myoculator, and special slides have been designed for the synoptophore to develop perception of depth.

\section{Aetiology}

A great number of cases have a family history of squint, especially those that come under the heading of periodic or occasional strabismus, but I am afraid that I cannot produce the exact percentages. It is stated in Worth's book on squint that the ideal age to develop binocular vision is between the ages of 3 to 5 years; between the ages of 5 to 6 years it is a lengthy process, and over 6 years of age it is not worth the trouble and time.

The following results, however, tend to show that the optimum age period can be extended a good deal further. The majority of patients who have attended for treatment are usually between the ages of 4 and 12 years, and up till then the results have been uniformly good. I have even a few cases that have developed binocular vision when over 20 years of age. The details of two of these will be discussed under the heading of unilateral strabismus.

Alternating divergent strabismus.-In the cases of alternating divergent strabismus where the angle of deviation is small and there is little or no binocular vision present, the results obtained by orthoptic treatment are good. If, however, the patient has good binocular vision on the synoptophore when first tested, it is much harder to effect a cure. Although there may be binocular vision the 
visual axes are not parallel ; it seems as if there must be some other 으․ element that has upset the equilibrium, or, maybe, there is present an $\overrightarrow{\overrightarrow{\mathrm{O}}}$ excessive exophoria which has broken down. However, the results of the treatment are obtained only if the patient issufficiently young, and if after some treatment the binocular vision shows signs of developing. (Needless to say it is necessary to have the co-operation of the child and the parent so that the treatment can be carried out at home.)

Where the angle of deviation exceeds $10^{\circ}$ to $15^{\circ}$ approximately, I have found that it was not always possible to effect a cure by orthoptics only. In these cases the exercises have proved extremely valuable as a preliminary and the patient has been taught to fuse and adduct a few degrees before the operation was performed ; after $\overrightarrow{0}$ the operation the treatment has been continued and stereoscopic vision developed.

CASE 1.-Alternating divergent concomilant strabismus.

J. P., aged 10 years. Emmetropic. Brother also has divergent strabismus. Angle ç of deviation on first visit $-15^{\circ}$. First grade of binocular vision, but no simultaneous macular perception present. After six lessons the angle of deviation was $8^{\circ}$ and 2 the fusion angle $0^{\circ}$. When I saw her three months after she had worked on fusional drawings and convergence exercises the angle of deviation was $-6^{\circ}$, the fusion angle $0^{\circ}$, she had $20^{\circ}$ of adduction and some stereoscopic vision. Five months later, during which time the exercises were overlooked, the angle of deviation was $-4^{\circ}$, the fusional angle $0^{\circ}$, stereoscopic vision good and power of adduction $30^{\circ}$. The eyes still diverge occasionally on looking into the distance and she is now working on an amblyoscope at home. Period taken, 10 treatments covering eight months.

CASE 2.-Alternating divergent concomitant strabismus.

M. R., aged 16 years. First squinted at 4 years of age; was left-handed and was trained to be right-handed. Emmetropic. Angle of deviation on first visit $\overrightarrow{\bar{O}}$ $-46^{\circ}$ with a left hyperphoria of 6 prism dioptres, and a right incyclophora $3^{\circ}$. She attended the clinic three days a week, after 18 lessons complained of diplopia and after 31 treatments acquired simultaneous macular perception, fusion and her power of adduction was $8^{\circ}$. Angle of deviation being $-38^{\circ}$ left hyperphoria 4 prism dioptres. She was then admitted into hospital and had the right internal rectus advanced and the right external rectus tenotomized. Eight days after, the degree was $0^{\circ}$ with a right hyperphoria of 7 prism dioptres. She attended daily $\div$ for a fortnight and then less frequently until she was able to manage a stereoscope $\underline{Z}$. at home. After 49 treatments, covering a period of five months, she had a good binocular vision, obtained Worth's four lights and was orthophoric on the Maddox rod test.

CASE 3.

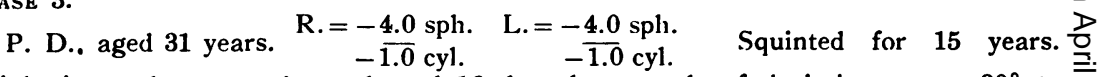
Right internal rectus advanced, and 16 days later angle of deviation was $-30^{\circ}$ to $\overline{\mathrm{N}}$ $-35^{\circ}$ and there was no binocular vision. By working on a strabismuscope at home $\Omega$ she has now obtained simultaneous macular perception and some degree of fusion, $\mathrm{N}$ but the angle of deviation has not decreased, and she does not wish for a further $\mathrm{N}$ operation.

*The angle of deviation is the actual angle of squint measured on the synoptophore, it differs from the fusion angle in so much as the slides used to determine it have no fusion element. The fusion angle generally tends to be greater than the angle of deviation when the fusion is very weak, but as the fusion strengbthens, the fusion angle decreases and becomes smaller than the angle of $\mathcal{D}$ deviation. 
Unilateral divergent strabismus.-On looking through the cases of unilateral strabismus, I find that they form several groups and are not all benefited by the same treatment.

In order that I may discuss the subject of divergent unilateral strabismus at length I shall grade the cases under the following headings :-

(1) Unilateral divergent strabismus.

(2) Unilateral divergent squint associated with hyperphoria and cyclophoria.

(3) Periodic or occasional divergent strabismus.

(1) In the case of a unilateral divergent strabismus associated with emmetropia where the degree of deviation was not excessive, and there was amblyopia present $I$ found that the results of the exercises were good. The good eye was occluded until the vision was equal, and the patient was taught to alternate whilst the treatment was in progress. The treatment consisted of developing the binocular vision by obtaining normal retinal correspondence and simultaneous macular perception, and I have found that it is not advisable to advance further until this stage has been reached. The patient was then taught to fuse and to appreciate perception of depth and then his power of adduction was developed. In the case of a unilateral divergent strabismus where there was a large deviation present, I found that after having taught the patient to alternate and having developed the binocular vision the degree had only lessened very slightly. It was necessary in this case, to assist the treatment by an operation, but before this was effected the patient had good fusion and some porwer of adduction.

I have a few cases of divergent squint which are associated with hypermetropia and on testing I found that the binocular vision on the synoptophore was good. This type of case has proved difficult to treat and is often rather lengthy. The patient is able to converge on a finger, but during the treatment is often given to "convergence spasms." What is the reason for this divergence? The visual axes are not straight and yet when tested on the instrument the binocular vision is found to be good. The unilateral divergent strabismus associated with hypermetropia where the binocular vision is not good has not proved difficult to train. Where the child is unable to alternate, the good eye is partially occluded until he is able to alternate at will, and as the binocular vision develops so the divergence decreases.

The cases of unilateral divergent strabismus associated with myopia have, in my opinion, taken longer to cure. In some cases the results were gratifying, but in others the myopia increased, 
whether this was progressive myopia or whether it was increased as a result of the treatment, I do not know, but the exercises were suspended.

The following are four cases that have been under treatment :One emmetrope, one myope, two hypermetropes, one with amblyopia and one with good binocular vision when first tested.

\section{CASE 4.-Right divergent concomitant strabismus.}

R. V., aged 19 years. Divergence noticed during last four years. Homonymous diplopia, although divergent on tests. Worth's lights, four momentarily, usually alternates. Attempts fusion at $-10^{\circ}$, although apparent angle of deviation is $-15^{\circ}$. After 13 lessuns obtained first grade of binocular vision with angle of deviation $-7^{\circ}$, right hyperphoria 3 to 5 prism dioptres. After 31 lessons obtained Worth's lights four. Maddox rod readings were exophoria $1^{\circ}$, wing $01-4$, convergence $55^{\circ}$. Stereoscopic vision good.

After 51 lessons over a period of two years and six months, angle of deviation $0^{\circ}$, binocular vision very good, Worth's lights four, rod exophoria $1^{\circ}$ to $1.5^{\circ}$, wing test orthophoric.

CASE 5.-Right divergent concomitant strabismus. R. and L. $+3.50 \mathrm{sph}$.

A. W., aged 6 years 6 months. Squinted from birth. Vision right eye 6/12 after one year's occlusion; angle of deviation $-9^{\circ}$; left hyperphoria 3 prism dioptres; Worth's lights five; no fusion. After 11 lessons over a period of 19 months visual acuity right eye $6 / 6$; angle of deviation -5 ; left hyperphoria 1 prism dioptre; angle of fusion $0^{\circ}$; adduction $15^{\circ}-20^{\circ}$; stereoscopic vision partial. Obtains four Worth's lights. Eyes nearly always straight. $\mathrm{He}$ is working on an amblyoscop\& to increase adduction.

CASE 6.-Left divergent concomitant strabismus.

P. P., aged 8 years. Age of onset seven years. Hypermetropic in both eye $\bar{s}^{+}$ $\frac{+1.0 \mathrm{sph} \text {. }}{+0.25 \mathrm{cyl}}$ Angle of deviation on first visit $-7^{\circ}$; fusion $-5^{\circ}$; adduction $5^{\circ}$. Partial stereopsis. Good convergence on one finger.

After 12 lessons, angle of deviation $-5^{\circ}$; fusion angle $0^{\circ}$; adduction $5^{\circ}$; stereoscopic vision better. Given drawings at home. After 27 lessons, angle of deviation $-5^{\circ}$; angle of fusion $0^{\circ}$; adduction $30^{\circ}$; stereoscopic vision good.

Eyes very variable. Left eye still diverges occasionally.

CASE 7.-Left divergent concomitant strabismus.

C. K., aged 9 years 6 months. First noticed occasionally at the age of nine months, re-appeared at three years as a constant squint.

R. $=-0.75 \mathrm{sph}$. L. $=-0.12 \mathrm{sph}$.

Angle of deviation $-17^{\circ}$. Right hyperphoria 4 prism dioptres, increasing to 6 prism dioptres looking to the right. Alternates on Worth's lights. Her binocular vision was good, but adductions very weak and stereoscopic vision only partially developed. Convergence on the finger good.

This child's treatment has been worked by a series of intensive courses of a fortnight with homework in the interim. At the end of her first fortnight's treatment the angle of deviation was $0^{\circ}$, and adductions $30^{\circ}$. She was given a Cruise stereoscope with Sattler's pictures to use at home.

When she was seen three months later for a test and nine months after this o for a second course of treatment, the angle of deviation was $-5^{\circ}$. After 40 treat- $N$ ments C. K. can control her eyes well, she squints occasionally; is orthophoric N on the Maddox rod test and maintains Worth's four lights, both with and without $\omega$ glasses.

I have no cases of unilateral divergent strabismus that have been operated on. 


\section{Orthoptic Treatment in Divergent Strabismus}

CASE 8.-Right divergent concomitant strabismus.

P. C., aged 9 years. Age of onset six years. R. $=-3.0 \mathrm{sph} . \mathrm{L} .=-1.5 \mathrm{sph}$.

Glasses given at 7 years of age. Angle of deviation on first visit $-10^{\circ}$ with a left hyperphoria of 2 prism dioptres. First grade of binocular vision.

After 14 treatments over a period of six weeks, it was found that the myopia in the right eye had increased. The treatment was discontinued with the exception of home exercises, however, these were also stopped owing to further progress of the myopia. This child has fusion and power of adduction is $4^{\circ}$. She is being kept under observation and probably will be operated on later.

(2) In the cases of a divergent squint associated with hyperphoria the treatment has proved very effective. Having obtained the first grade of binocular vision, the fusion sense and stereoscopic vision are then developed. When this stage is achieved the supra- and infra-adductions are trained and convergence is increased to $40^{\circ}$ or $50^{\circ}$.

\section{CASE 9.-Right divergent concomitant strabismus.}

$\mathrm{N}$. C., aged 13 years 6 months. Was ordered $+1.25 \mathrm{sph}$. when a left concomitant strabismus, and became a left divergent concomitant strabismus, so glasses were discontinued.

Angle of deviation when first seen $-10^{\circ}$ with a right hyperphoria of 9 prism dioptres, and a right in-cyclophoria $5^{\circ}$. She had first grade binocular vision but no fusion. On the Maddox rod test the exophoria was $10^{\circ}$, and the hyperphoria $18^{\circ}$, on the Maddox wing test the exophoria was $22^{\circ}$ and the hyperphoria $8^{\circ}$.

She attended daily for treatment for a fortnight and then three days a week. After 24 treatments the angle of deviation was $0^{\circ}$ with a hyperphoria of 3 prism dioptres, the readings on the Maddox rod were exophoria $7^{\circ}$ to $8^{\circ}$; hyperphoria $5^{\circ}$; and on the wing test exophoria $2^{\circ}$ and hyperphoria $2^{\circ}$.

After 30 lessons covering a period of three months she was discharged with good binocular vision. Readings on the wing test orthophoric and on the rod test hyperphoria 0.5 prism dioptre and exophoria $1^{\circ}$.

When seen during the next year she was orthophoric in both rod and wing tests.

A similar case to the above is one where the divergence is associated with cyclophoria instead of hyperphoria.

These cases of divergent strabismus wih hyperphoria or cyclophoria are very interesting and react extremely well to treatment if there is some defect in the binocular vision. As the binocular vision develops and the fusion is strengthened the hyperphoria and cyclophoria gradually decrease until the patient can fuse at $0^{\circ}$ (on the synoptophore). When this is obtained and he is able to adduct a few degrees, and has acquired some stereoscopic vision it will be found that the hyperphoria or cyclophoria will have disappeared. Occasionally, when the hyperphoria has not disappeared it has been found necessary to train the supra- and infra-ductions.

CASE 10.-Right divergent concomitant strabismus. R. $=+2.0 . \quad \mathrm{L} .=+0.25$.

(For reading only.)

C. D., aged 29 years. First squinted between the age of two and three years; attributed cause, whooping cough. Angle of deviation on first visit $-18^{\circ}$ right hyperphoria 7 prism dioptres (variable) and right in-cyclophoria $15^{\circ}$, no fusion. After 13 lessons angle of deviation $4^{\circ}$, obtained fusion at $0^{\circ}$ with a right hyperphoria of 2 prism dioptres; adductions $5^{\circ}$. After 23 lessons angle of deviation $0^{\circ}$; angle of fusion $0^{\circ}$; adduction $25^{\circ}$; stereoscopic vision fairly good. 
C. D. still allows the right eye to wander when tired, but is continuing to use her amblyoscope and is satisfied with her result.

Treatments, 23 over a period of nine and a half months.

(3) The high percentage of these occasional or periodic squints found in young children is interesting. The history of very case is very similar.

1. Usually there is no refractive error.

2. A history of one wandering since birth or within the first year.

3. Hereditary history.

4. These cases are rarely associated with amblyopia.

Of the 93 cases of divergent strabismus which I have seen, $22 \cdot \overrightarrow{-}$ were of this type. Of these 22 cases, 17 were emmetropic. Of $\underset{v}{\omega}$ these 17 cases, 13 were noted from birth or within the first year. 옹

Of these 13 cases, seven have a family history of strabismus.

In these cases the eyes appear to be straight, except on covering, or when the child is tired or looking into the distance. On examination of these cases I have found that there is usually $15^{\circ}>$ to $25^{\circ}$ of divergence and little or no binocular vision present $\overrightarrow{0}$ They respond well to orthoptic treatment, but the results are ne quickly or easily obtained.

There is little difficulty in achieving normal retinal corres? pondence, but the development of the fusion sense has been unusually slow. The cases have been taught to fuse on the synopto- $\frac{}{\circ}$ phore, by using two similar pictures with small control marks on $\stackrel{\mathbb{Q}}{\mathbb{2}}$ each, which they superimpose. They practise at home on the $\overrightarrow{\vec{O}}$ cheiroscope and strabismuscope with toys and tracings. This stage 3 accomplished, they are taught to appreciate perception of depth and then their adduction or fusional convergence is increased to about $40^{\circ}$ or $50^{\circ}$.

\section{CASE 11.-Left divergent concomitant strabismus.}

J. W., aged 7 years 6 months. Squinted since birth. (Grandmother has a squint, emmetropic.) Angle of deviation $-15^{\circ}$, alternates on Worth's lights. Weak fusion. Given a cheiroscope with toys and drawings for home use, and a Cruise stereoscope. Seven months later angle of deviation $-5^{\circ}$; fusion angle $0^{\circ}$; adductions $20^{\circ}$. Partial stereoscopic vision. Has now an amblyoscope at home, angle of deviation $0^{\circ} ;$ fusion angle $0^{\circ}$; adduction $30^{\circ}$. Stereoscopic vision good. Worth's lights four. Treatments, 13. Period, one year.

CASE 12.-Left divergent concomitant strabismus.

G. H., aged 7 years. Squinted since birth. Eyes appeared straighter after three $\mathrm{N}$ weeks, but squint reasserted about 4 years of age. Emmetropic. Angle of deviation $\omega$ $-20^{\circ}$, left hyperphoria 4 prism dioptres. No fusion. Attended the clinic three $\bar{\gamma}$ times a week for nearly three months. Angle of deviation $-20^{\circ}$; fusion angleco $-20^{\circ}$; adduction $10^{\circ}$. Given fusional drawings at home and although the degree $\frac{\bar{C}}{D}$ of deviation is still $-15^{\circ}$, the fusion angle is $0^{\circ}$. The power of adduction is $15^{\circ}, \stackrel{\infty}{\rightarrow}$ 
and stereoscopic vision is partially developed. The left eye was seen to wander occasionally. She is, however, continuing to use the amblyoscope to increase the power of adduction to $40^{\circ}$.

CASE 13.-Left divergent concomitant strabismus.

O. P., aged 25 years. Squinted since 8 years of age. "Due to a bad fall." Emmetropic. Angle of deviation on first treatment $-13^{\circ}$ with a right hyperphoria of 4.5 prism dioptres. Maddox rod test, exophoria $20^{\circ}$. She was unable to fuse or put the lion in the cage (simultaneous macular perception) on her first visit, due to a large area of suppression. At her fourth lesson she was given an amblyoscope. She returned intermittently for treatment, and after four and a half months, having attended the clinic eight times she had simultaneous macular perception, fusion, stereoscopic vision and $30^{\circ}$ of adduction. The readings on the Maddox rod and wing test were orthophoric.

A similar type of case to the above, which is not often seen, is one in which the eye diverges only on covering, but otherwise appears to be straight. When this patient with a divergence of $10^{\circ}$ to $15^{\circ}$, obtained the first grade of binocular vision, he over accommodated and the degree of deviation instead of being negative angle was positive. These patients are taught to relax their accommodation and the convergence decreases, but no effort is made to train their powers of adduction until stereoscopic vision is well developed. Of the few cases I have seen of this type, all have been emmetropic with the exception of one which was myopic.

CASE 14.

P. H., aged 12 years 6 months. Age of onset 5 to 6 years. Alternates on Worth's lights. Angle of deviation $-15^{\circ}$; right hyperphoria 7 prism dioptres fixing right eye. Angle of deviation $-15^{\circ}$ no hyperphoria fixing left eye. Objective reading $-15^{\circ}$; subjective $-10^{\circ}$. Therefore, abnormal retinal correspondence. After seven lessons obtained normal right correspondence at $0^{\circ}$. Whilst endeavouring to obtain simultaneous macular perception the angle of the deviation increased to $+20^{\circ}$. , i.e., $20^{\circ}$ of convergence and he was unable to see clearly when the lion was in the cage. After 13 lessons the angle of deviation was $+20^{\circ}$; fusion $+15^{\circ}$; no stereoscopic vision.

He went away for the holidays, taking a strabismuscope on which he practised fusion drawings. He found these extremely difficult as he was unable to keep the outline clear. However, he continued treatment at home on a synoptophore, and when I saw him two months later he had stereoscopic vision, but he also had $15^{\circ}$ of convergence on the rod and wing tests and yet the eyes were still diverging.

$\mathrm{He}$ has been attending twice a week for the first half of his school term and then once a week. He is now at $0^{\circ}$ on the synoptophore; has $40^{\circ}$ adductions; $10^{\circ}$ of adduction; good stereoscopic vision. On the Maddox rod the readings are orthophoric, and on the wing test $01-2$ at the beginning and end of the lesson, but he still complains of diplopia when looking at aeroplanes! He is now working on the myoculator on up and down movements, and a small diploscope.

Treatments, 33. Period, eight months.

One of the most difficult cases to cure is the divergent squint due to an operation, or a convergent strabismus where the internal rectus has been too freely tenotomized. In some cases where the eyes are only slightly divergent, by strengthening the binocular vision it is possible to straighten the eyes. However, in others 
where there is no binocular vision present or when the fusion is weak, the eye becomes slightly proptosed and slowly more and more divergent. In these cases it has been necessary to re-attach $\overrightarrow{0}$ the internal rectus.

\section{Summary}

From the point of view of treatment, cases may be considered $\stackrel{\mathscr{c}}{\circ}$ under the following headings :-

(1) Divergent strabismus curable by orthoptic treatment only.

(a) Alternating strabismus with small angle.

(b) Unilateral strabismus with small angle.

(c) Divergent strabismus associated with hyperphoria and cyclophoria.

(d) Periodic or occasional divergent strabismus.

(2) Divergent strabismus curable only by operation together with orthoptic treatment.

(a) Alternating divergent strabismus with an angle larger $\overrightarrow{0}$ than $10^{\circ}$ to $15^{\circ}$ approximately.

(b) Unilateral divergent strabismus with a large angle.

(c) Post-operative divergence.

The conclusions which I wish to emphasize are :-

(1) Cases of divergent strabismus benefit from orthoptic treatment whether they can be cured by treatment alone or whether they will need an operation.

(2) The majority of cases seen are cured by orthoptic treatment alone without operation.

(3) The percentage of emmetropic cases is very high and the majority of them come under the heading of periodic or occasional divergent strabismus.

(4) There are very few divergent squints associated with $\frac{7}{0}$ amblyopia. 